\title{
International Robust Disagreement
}

\author{
By Riccardo Colacito and Mariano M. Croce*
}

We characterize the equilibrium of a two-country, two-good economy in which agents have opposite bias toward one of the two consumption goods and fear model misspecification. We document that disagreement about endowments' growth prospects is a natural outcome of this class of economies.

Why do countries disagree about their relative growth opportunities? In this paper we propose an answer that relies on both consumption home bias and concerns about model misspecification.

The economy is populated by two agents, home and foreign, each endowed with the stochastic supply of one country-specific good. Endowments are i.i.d. and less than perfectly correlated. In each country, preferences are biased toward the domestic good. Trade occurs in frictionless goods markets and in financial markets featuring a complete set of state- and date-contingent securities.

The assumption of consumption home bias is crucial to generate endogenous heterogenous beliefs. When agents fear model misspecification, they slant probabilities toward worst case outcomes. Since each country in our economy fears a low supply of its most preferred good, the worst case scenario is effectively country specific. This results in different expectations about the growth rates of the local endowments even in the case in which all goods share the same objective probability distribution.

This paper builds on a long strand of the literature on robust control (Hansen and Sargent (2005), Hansen and Sargent (2007)) and on the literature of risksharing with heterogenous consumers with recursive preferences (see Anderson (2005), Colacito and Croce (2011), and Borovicka (2011)).

\section{The economy}

Endowments. In our economy there exist two goods, $X$ and $Y$, whose endowments are stochastic Markov processes. Let $s_{t}$ and $s^{t}=\left(s_{0}, \ldots, s_{t}\right)$ denote the realization of a random event at and an history of events up to time $t$, respectively. We assume that endowments in period $t$ are (i) time-invariant measurable functions of $s_{t}$ so that $\left(X_{t}\left(s^{t}\right), Y_{t}\left(s^{t}\right)\right)=\left(X_{t}\left(s_{t}\right), Y_{t}\left(s_{t}\right)\right)$, and (ii) i.i.d., hence $\pi\left(s_{t} \mid s^{t-1}\right)=\pi\left(s_{t}\right)$. For each history $s^{t-1}$, let there be only two equally likely states for time $t: s_{t}^{H L}=\frac{X_{t}\left(s^{t}\right)}{Y_{t}\left(s^{t}\right)}=k$ and $s_{t}^{L H}=\frac{X_{t}\left(s^{t}\right)}{Y_{t}\left(s^{t}\right)}=1 / k$, for some $k>1$. Accordingly, we index all equilibrium prices and quantities with a superscript $H L$ or $L H$, depending on which of the two i.i.d. states materializes.

* Both authors are affiliated with the University of North Carolina at Chapel Hill, Kenan-Flagler Business School. 
Preferences. The economy consists of two countries, home $(h)$ and foreign $(f)$, each populated by a representative agent with a preference for robustness as in Hansen and Sargent (2007):

$$
U_{i, t}\left(s^{t}\right)=(1-\delta) \log C_{i, t}\left(s^{t}\right)+\delta \boldsymbol{T}^{\mathbf{1}}\left(U_{i, t+1}\left(s_{t+1} \mid s^{t}\right)\right)
$$

where

$$
\boldsymbol{T}^{\mathbf{1}}\left(U_{i, t+1}\left(s_{t+1} \mid s^{t}\right)\right)=\theta \log \sum_{s_{t+1}} \exp \left\{\frac{U_{i, t+1}\left(s_{t+1} \mid s^{t}\right)}{\theta}\right\} \pi\left(s_{t+1} \mid s^{t}\right), \quad \forall i \in\{h, f\} .
$$

The operator $\boldsymbol{T}^{\mathbf{1}}$ captures the attitude of an agent that chooses a worst-case distortion to the conditional distribution of consumption in order to account for the present value of an entropy penalty. This penalty limits the set of alternative models against which each agent guards. The size of that set is constrained by the parameter $\theta$ and it is increasing in $\theta$, with $\theta=-\infty$ signifying the absence of a concern for robustness.

Home and foreign consumption bundles are aggregates of good $X$ and good $Y$ :

$$
C_{h, t}=x_{h, t}^{\alpha} y_{h, t}^{1-\alpha} \quad \text { and } \quad C_{f, t}=x_{f, t}^{1-\alpha} y_{f, t}^{\alpha}
$$

where $x_{i, t}$ and $y_{i, t}$ denote the consumption of good $X$ and good $Y$ in country $i \in$ $\{h, f\}$ at date $t$. Since we endow the home country with good $X$ and the foreign country with good $Y$, setting $\alpha>1 / 2$ introduces a symmetric consumption home bias across the two goods.

Markets. At each date, agents can trade goods and a complete set of oneperiod-ahead state-contingent securities. At each date $t>0$, the budget constraints of the home and foreign agents are as follows:

$x_{h, t}\left(s^{t}\right)+p_{t}\left(s^{t}\right) y_{h, t}\left(s^{t}\right)+\sum_{s_{t+1}} q_{t}\left(s_{t+1} \mid s^{t}\right) a_{h, t+1}\left(s_{t+1}, s^{t}\right) \leq X_{t}\left(s^{t}\right)+a_{h, t}\left(s^{t}\right)$
$x_{f, t}\left(s^{t}\right)+p_{t}\left(s^{t}\right) y_{f, t}\left(s^{t}\right)-\sum_{s_{t+1}} q_{t}\left(s_{t+1} \mid s^{t}\right) a_{h, t+1}\left(s_{t+1}, s^{t}\right) \leq p_{t}\left(s^{t}\right) Y_{t}\left(s^{t}\right)-a_{h, t}\left(s^{t}\right)$,

where $p_{t}\left(s^{t}\right)$ denotes the relative price of good $Y$ and $\operatorname{good} X, a_{i, t}\left(s^{t}\right)$ denotes country $i$ 's claims to time $t$ consumption of good $X$, and $q_{t}\left(s_{t+1} \mid s^{t}\right)$ gives the price of one unit of time $t+1$ consumption of good $X$, contingent on the realization $s_{t+1}$ at $t+1$, when the history at $t$ is $s^{t}$.

\section{Solution of the model}

Pareto problem. Efficient allocations can be computed as the solution to the planner's problem. The planner attaches nonnegative Pareto weights $\mu_{h}=\mu$ and $\mu_{f}=1-\mu$ on the consumers and chooses allocations $\left\{\left(x_{i, t}\left(s^{t}\right), y_{i, t}\left(s^{t}\right)\right)\right\}_{t=0}^{+\infty}$, 
$i \in\{h, f\}$ to maximize

$$
Q\left(s_{0}\right)=\mu U_{h, 0}\left(s_{0}\right)+(1-\mu) U_{f, 0}\left(s_{0}\right),
$$

subject to a sequence of two economy-wide feasibility constraints:

$$
\begin{aligned}
x_{h, t}\left(s^{t}\right)+x_{f, t}\left(s^{t}\right) & \leq X_{t}\left(s^{t}\right) \\
y_{h, t}\left(s^{t}\right)+y_{f, t}\left(s^{t}\right) & \leq Y_{t}\left(s^{t}\right) .
\end{aligned}
$$

Anderson (2005) suggests a recursive way to characterize this problem in a onegood economy, and Colacito and Croce (2011) extend this technique to multiplegoods economies. The insight is that the solution can be conveniently cast in terms of a time-varying vector of Pareto weights. Let $\mathcal{M}_{t}\left(s^{t}\right)=\mu_{h, t}\left(s^{t}\right) / \mu_{f, t}\left(s^{t}\right)$ denote the time $t$ history $s^{t}$ ratio of Pareto weights. The optimal consumption allocation rule is a sequence of functions that maps a history $s^{t}$ into a choice of time $t$ consumption of each good in each country:

$$
\begin{aligned}
x_{h, t}\left(s^{t}\right) & =\frac{\alpha \mathcal{M}_{t}\left(s_{t} \mid s^{t-1}\right)}{(1-\alpha)+\alpha \mathcal{M}_{t}\left(s_{t} \mid s^{t-1}\right)} X_{t}\left(s_{t}\right), & x_{f, t}\left(s^{t}\right) & =\frac{(1-\alpha)}{(1-\alpha)+\alpha \mathcal{M}_{t}\left(s_{t} \mid s^{t-1}\right)} X_{t}\left(s_{t}\right) \\
y_{h, t}\left(s^{t}\right) & =\frac{(1-\alpha) \mathcal{M}_{t}\left(s_{t} \mid s^{t-1}\right)}{\alpha+(1-\alpha) \mathcal{M}_{t}\left(s_{t} \mid s^{t-1}\right)} Y_{t}\left(s_{t}\right), & y_{f, t}\left(s^{t}\right) & =\frac{\alpha}{\alpha+(1-\alpha) \mathcal{M}_{t}\left(s_{t} \mid s^{t-1}\right)} Y_{t}\left(s_{t}\right),
\end{aligned}
$$

where

$$
\begin{aligned}
\mathcal{M}_{t}\left(s_{t} \mid s^{t-1}\right)= & \mathcal{M}_{t-1}\left(s^{t-1}\right) \cdot \\
& \frac{\exp \left\{\frac{U_{h, t}\left(s_{t} \mid s^{t-1}\right)}{\theta}\right\}}{\sum_{s_{t}} \exp \left\{\frac{U_{h, t}\left(s_{t} \mid s^{t-1}\right)}{\theta}\right\} \pi\left(s_{t} \mid s^{t-1}\right)} / \frac{\exp \left\{\frac{U_{f, t}\left(s_{t} \mid s^{t-1}\right)}{\theta}\right\}}{\sum_{s_{t}} \exp \left\{\frac{U_{f, t}\left(s_{t} \mid s^{t-1}\right)}{\theta}\right\} \pi\left(s_{t} \mid s^{t-1}\right)},
\end{aligned}
$$

$\forall t \geq 1$ and $\mathcal{M}_{0}\left(s_{0}\right)=\mu /(1-\mu)$. By interpreting the Pareto weights as time varying, consumption allocation rules have the above straightforward representation, and the Pareto problem can be written recursively. More importantly, the innovation in the ratio of the Pareto weights is equal to the ratio of the increments of the home and foreign distortion martingales. This makes the allocations functions of the history of disagreements on distorted probabilities.

Calibration. We calibrate the endowments to be equal to 100 in the lowsupply state and $k=1.031$ The coefficient of risk aversion $\gamma$ is set to 25 and the subjective discount factor $\delta$ to 0.95 to reflect a yearly decision problem. Home bias is embedded in the parameter $\alpha=0.98$.

\footnotetext{
${ }^{1}$ The properties of the risk-sharing scheme do not depend on the level of the endowments, as far as they are bounded away from zero. We choose a level of 100 simply for numerical reasons. The parameter $\kappa=1.03$ is chosen to have a moderate amount of volatility in the growth rate of the two goods.
} 


\section{International Endogenous Disagreement}

The solution of the robust min-max problem results in the following agentspecific distorted conditional distribution of the endowment processes:

$$
\begin{aligned}
& \tilde{\pi}_{i, t+1}^{H L}\left(s^{t}\right)=\pi\left(s_{t+1} \mid s^{t}\right) \frac{\exp \left\{U_{i, t+1}^{H L}\left(s^{t}\right) / \theta\right\}}{\sum_{s_{t+1}} \exp \left\{U_{i, t+1}\left(s_{t+1} \mid s^{t}\right) / \theta\right\} \pi\left(s_{t+1}\right)} \\
& \widetilde{\pi}_{i, t+1}^{L H}\left(s^{t}\right)=\pi\left(s_{t+1} \mid s^{t}\right) \frac{\exp \left\{U_{i, t+1}^{L H}\left(s^{t}\right) / \theta\right\}}{\sum_{s_{t+1}} \exp \left\{U_{i, t+1}\left(s_{t+1} \mid s^{t}\right) / \theta\right\} \pi\left(s_{t+1}\right)}, \quad \forall i \in\{h, f\} .
\end{aligned}
$$

Since each of the distorted probabilities in equation (2) depends on the utility of a specific agent, our agents disagree on the transition probabilities across states of the world. To better explain this point, in the top two panels of figure 1, we depict distorted conditional probabilities as a function of $\mu_{t}\left(s^{t}\right)=\mathcal{M}_{t} /\left(1+\mathcal{M}_{t}\right)$, a measure of the disagreement across our two countries. By comparing the left and right panels of figure 1, it is possible to see that the distorted probabilities are country-specific. This is a reflection of the fact that agents with heterogenous preferences have heterogenous assessments of the worst-case scenario.

Robustness slants probabilities toward the worst-case outcomes. In our economy with multiple goods and home bias, however, the definition of worst-case event changes endogenously and in an intuitive fashion. On the one hand, when $\mu_{t}\left(s^{t}\right)$ is close to unity, the home agent faces the possibility of being alone in the economy. In this case, she fears a scarce supply of her most-preferred good, i.e, $s_{t}^{L H}$ is the worst event. On the other hand, when $\mu_{t}\left(s^{t}\right)$ approaches zero, the home agent faces the prospect of being wiped out of the economy. Via the endogenous risk-sharing scheme, the realization of a high relative supply of local good, $s_{t}^{H L}$, would reduce even further the future share of resources. That is, $s_{t}^{H L}$ becomes the worst event. The assessment of the worst-case scenario is perfectly reversed for the foreign country.

The distortion of conditional probabilities has the effect of distorting conditional moments of the marginal distributions of the endowments. The middle four panels of figure 1 report distorted conditional expectations $\widehat{E}(X)$ and $\widehat{E}(Y)$ and distorted conditional volatilities $\widehat{\sigma}(X)$ and $\widehat{\sigma}(Y)$ of the two endowments in the two countries. Distorted conditional expectations are the mirror image of distorted probabilities. The preference for robustness tends to lower the expected supply of one country's domestic good relative to the other country's good as a function of the domestic Pareto weight. Conditional second moments are distorted in such a way that (i) within each country the relative riskiness of the two endowments is constant as under the original probability measure, and (ii) volatility prospects are different across countries except when $\mu_{t} \in\{0,1 / 2,1\}$. The bottom two panels document that the distorted conditional correlations are unaffected by the concern for robustness. 

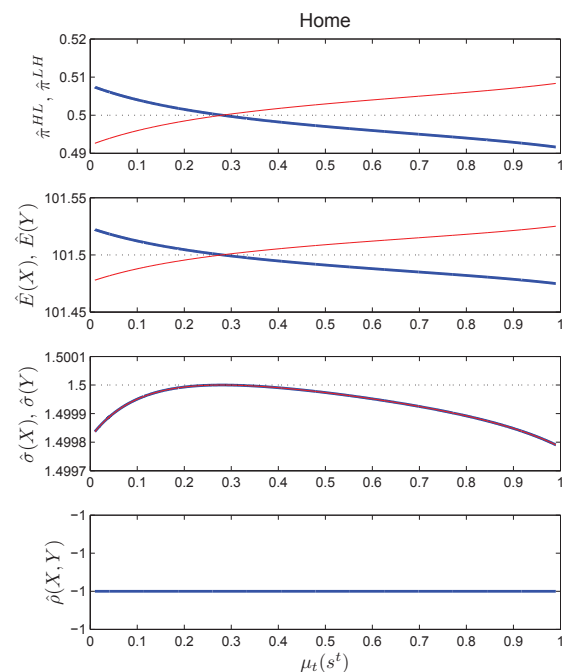
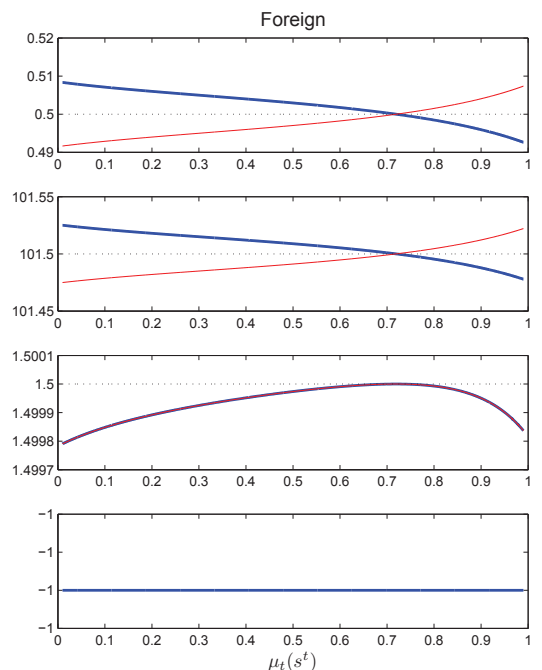

Figure 1. Distorted distributions. The left (right) Column reports distorted probabilities AND CONDitional moments of the home (FOREign) COUntry. The thin Line Refers to the $L H$ State, While the thiCK Line Refers to the $H L$ State. The DotTed line Refers to the undistorted PROBABILITIES AND MOMENTS OBTAINED WHEN $\theta=-\infty$.

\section{Concluding remarks}

We show that introducing robustness concerns in a complete markets, twocountry, two-good economy endogenously generates international disagreement about growth prospects. Future developments of this literature should consider the role of both financial and information frictions. A formal estimation of a fully fledged model allowing for heterogeneity and capital accumulation would shed light on the deep origins of international prices and quantities.

\section{REFERENCES}

Anderson, Evan, "The dynamics of risk-sensitive allocations," Journal of Economic Theory, 2005, 125(2), 93-150.

Borovicka, Jaroslav, "Survival and long-run dynamics with heterogeneous beliefs under recursive preferences," University of Chicago Working Paper, 2011.

Colacito, Riccardo and Mariano M. Croce, "Recursive allocations and wealth distribution with multiple goods: existence, survivorship, and dynamics," Working Paper, UNC, Chapel Hill, 2011.

Hansen, Lars P. and Thomas J. Sargent, "Robust Estimation and Control under Commitment," Journal of Economic Theory, 2005, 124(2), 258-301.

and ., "Robust Estimation and Control without Commitment," Journal of Economic Theory, 2007, 136(1), 1-27. 